\title{
Quantification of myocardial perfusion in clinical trials
}

\author{
Mario Petretta, MD, ${ }^{\mathrm{a}}$ Carmela Nappi, $M{ }^{\mathrm{b}}{ }^{\mathrm{b}}$ and Alberto Cuocolo, $\mathrm{MD}^{\mathrm{b}}$ \\ ${ }^{a}$ Department of Translational Medical Sciences, University Federico II, Naples, Italy \\ b Department of Advanced Biomedical Sciences, University Federico II, Naples, Italy
}

doi: $10.1007 / \mathrm{s} 12350-014-0003-5$

\section{See related article, pp. 248-261}

In the current era of comparative effectiveness and outcomes research, ${ }^{1}$ it is mandatory to have robust estimators of disease, also useful for risk stratification and healthy decision-making. ${ }^{2}$ Myocardial perfusion imaging with electrocardiographic gated single-photon emission computed tomography (SPECT) is widely used for diagnostic purpose and for risk stratification of patients with suspected or known coronary artery disease. ${ }^{3}$ However, improving nuclear cardiology practice is required to maximize its role in the presence of multiple concurrent imaging modalities.

\section{REGADENOSON SPECT MYOCARDIAL PERFUSION IMAGING}

The United States Food and Drug Administration approved the use of regadenoson, a selective adenosine A2A receptor agonist, on April 10, 2008 for SPECT myocardial perfusion imaging as vasodilator stress agent. ${ }^{4}$ In patients undergoing SPECT myocardial perfusion imaging, regadenoson induces an increase in coronary blood flow similar to adenosine. Advantages of regadenoson over adenosine and dipyridamole include its rapid onset of maximal hyperemia ( $<1$ minute), short duration of action, and fixed-dose bolus administration. ${ }^{5}$ In clinical settings, these advantages translate to a shorter stress protocol and more rapid patient throughput. In addition, regadenoson may be used safely in

\footnotetext{
Reprint requests: Alberto Cuocolo, MD, Department of Advanced Biomedical Sciences, University Federico II, Via Pansini 5, 80131 Naples, Italy; cuocolo@unina.it

J Nucl Cardiol 2015;22:262-5.

1071-3581/\$34.00

Copyright (C) 2014 American Society of Nuclear Cardiology.
}

patients with asthma, chronic obstructive pulmonary disease, and end-stage kidney, and liver disease. ${ }^{6}$

Cerqueira et $\mathrm{al}^{7}$ combined data from two identical double-blind, randomized, active comparator, double dummy, multicenter phase three trials, the ADVANCE MPI (ADenoscan Versus regAdenosoN Comparative Evaluation for Myocardial Perfusion Imaging) 1 and 2 designed to show the strength of agreement between sequential adenosine-regadenoson images. Using visual assessment of serial SPECT images for detection of ischemia relative to adenosine, non-inferiority of regadenoson was demonstrated for all patients and detection of ischemia was also comparable in specific subgroups. However, the average agreement rate between adenosineadenosine and adenosine-regadenoson were $0.62 \pm 0.03$ and $0.63 \pm 0.02(P=\mathrm{NS})$. Agreement was less for both agents in women vs men with moderate and large areas of ischemia. This is not surprising based on the significantly greater variability associated with visual as compared to quantitative analysis of SPECT images. ${ }^{8}$ In a subsequent study, ${ }^{9}$ the same group of investigators used quantitative SPECT analysis to determine the total left ventricular (LV) perfusion defect size and extent of ischemia in patients enrolled in the ADVANCE MPI 2 study randomized in a 2:1 ratio to either regadenoson $(n=495)$ or a second adenosine SPECT $(\mathrm{n}=260)$ after a standard gated SPECT myocardial perfusion imaging. A single observer who was blinded to randomization and image sequence performed quantification. In this analysis, applying quantitative analysis, regadenoson induced virtually identical scintigraphic results as adenosine regarding the size and severity of LV perfusion defects and the extent of scintigraphic ischemia. In this sub study analysis of the ADVANCE MPI 2, a quantitative approach was taken to better characterize the similarity in perfusion results observed between adenosine and regadenoson over the visual assessment used in the original study design. ${ }^{7,10}$ Quantitative SPECT analysis was performed using a previously validated automated 
program, currently incorporated within the 4 DimensionMyocardial (4DM) SPECT, developed at the University of Michigan Medical Center (Ann Arbor, MI). ${ }^{11}$ This quantitative software program provides automated processing, analysis, and reporting of myocardial perfusion and function from cardiac SPECT studies and determines the extent and severity of the stress-induced perfusion defects and the extent of scar and ischemia based on polar plot analysis.

In this issue of the journal, Mahmarian et $\mathrm{al}^{12}$ extended the findings of ADVANCE MPI 2 study to all patients enrolled in the two ADVANCE MPI trials and evaluated the comparability of quantitative analysis of regadenoson vs adenosine-induced perfusion abnormalities across different patient populations based on age, gender, body mass index, diabetic status, and prior history of cardiovascular disease. It appears that regadenoson induces perfusion abnormalities similar to those observed with adenosine irrespective of patient clinical characteristics or cardiac history. Accordingly, the authors suggest (but not demonstrated due to the lack of follow-up data) that regadenoson should provide comparable diagnostic and prognostic SPECT information to that obtained with adenosine and across heterogeneous patient populations. ${ }^{12}$

\section{QUANTITATIVE SPECT MYOCARDIAL PERFUSION IMAGING}

Visual analysis of myocardial perfusion imaging is intrinsically subjective and subject to intra- as well as inter-readers variability. Conversely, quantitative programs, using as reference for comparing normal databases, can be used with little or no operator interaction and the results are more reproducible. In fact, accounting for potential artifacts, such as breast, lateral chest wall or diaphragm attenuation, and defining a standard results template that eliminated variations resulting from differences in body habitus and orientation, quantitative software packages allow better interstudy comparisons. However, also if appealing as compared to visual, quantitative analysis of myocardial perfusion still presents areas of uncertainty and some limitations. As an example, unrecognized artifacts, such as those introduced by motion or other suboptimal quality issue, not accounted for in comparison with the normal database, may be interpreted as abnormal findings with automatic quantification.

Since the study of Garcia et al, ${ }^{13}$ many approaches to SPECT imaging quantification have been described. ${ }^{14}$ The most widely used software packages to determine myocardial perfusion and LV function are: quantitative perfusion SPECT (QPS)/quantitative gated SPECT (QGS), developed at the Cedars-Sinai Medical Center
(Los Angeles, CA $)^{15}$; Emory Cardiac Toolbox (ECTb), developed at the Emory University (Atlanta, GA) ${ }^{16}$; and 4DM SPECT. ${ }^{11}$ There are limited data on the degree of agreement between these methods in quantifying the perfusion pattern and $\mathrm{LV}$ function. Wolak et $\mathrm{al}^{17}$ performed a detailed comparison of these three software tools with respect to automation and diagnostic performance in the detection of coronary artery disease in a large group of patients with available coronary angiography results and in patients with a low likelihood of disease. Normalcy rate was higher for QPS and 4DM vs ECTb, at $91 \%$ and $94 \%$ vs $77 \%$, respectively $(P=.02)$. Sensitivity was higher for QPS $(87 \%)$ vs 4DM $(80 \%)$ $(P=.045)$. Specificity was higher for QPS $(71 \%)$ vs ECTb $(49 \%)(P=.01)$. The accuracy rate was higher for QPS vs 4DM and ECTb, at $83 \%$ vs $77 \%$ and $76 \%$, respectively $(P=.05)$. Therefore, there were significant differences in myocardial perfusion quantification, diagnostic performance, and degree of automation of software packages. ${ }^{17}$ Ather et al $^{18}$ more recently examined the correlation and agreement among these three programs in assessing perfusion defect size and reversible defect size (by polar maps) as well as LV ejection fraction, end-diastolic volume, end-systolic volume, and mass. Data were collected from 120 consecutive patients who had abnormal regadenoson SPECT myocardial perfusion imaging with a visually derived summed stress score $\geq 4$ at Birmingham Medical Center (University of Alabama). The correlation between the software programs for measurements of perfusion defect size, reversible, and fixed defects was poor to fair (Spearman's $\rho=0.18-0.72$ ). Overall, estimation of defect size was smaller by QPS and larger by 4DM-SPECT. There was discordance among the softwares in $62 \%$ of the cases in defining perfusion defect size as small/moderate/large. The correlation between the softwares was better for measuring LV ejection fraction, volumes and mass ( $\rho=0.84-0.97)$, and discrepant results for defining normal/mild-moderate/severe LV systolic dysfunction were prevalent in $28 \%$ of the patients. These findings demonstrate that there are significant differences between the softwares in measuring perfusion defect size as well as LV function, and more importantly in defining small, moderate, or large ischemic burden.

The results of Wolak et $\mathrm{al}^{17}$ and Ather et $\mathrm{al}^{18}$ are not an absolute novelty. In 1997, preliminary data of a comparison of quantification of SPECT defect sizes by four different software programs, as well classification of defect abnormalities by four well-known laboratories and experts found a reasonable overall correlation of quantitative and visual defect sizes but demonstrated a substantial spread at Bland-Altman analysis of individual data points particularly for large defects. ${ }^{19}$ 
Therefore, although there was a good relative correlation of quantified defect sizes, no such agreement was achieved for absolute measurements and classification. Since the extension and severity of ischemic burden on stress myocardial perfusion imaging have an important diagnostic and prognostic value, a uniformly accepted unit of defect size is crucial for evidence-based patient management. Moreover, as a novel research application of myocardial perfusion imaging is the use of paired/ serial imaging to compare the relative effectiveness of treatments within the framework of randomized controlled trials ${ }^{20}$ there is the necessity of using the same software when assessing interval changes by serial imaging.

\section{IMPACT OF ATTENUATION CORRECTION}

Both studies by Wolak et $\mathrm{al}^{17}$ and Ather et $\mathrm{al}{ }^{18}$ only considered data without attenuation correction. Although some studies reported an increase in the diagnostic accuracy for the detection of coronary artery disease when myocardial perfusion SPECT is attenuation corrected, ${ }^{21-23}$ only a few investigations addressed the accuracy of attenuation correction without any visual interpretation of corrected and non-corrected data. ${ }^{24-27}$ To avoid any possible bias associated with visual interpretation, in another study Wolak et $\mathrm{al}^{28}$ evaluated the performance of attenuation correction in 2,624 women by using automated quantitative analysis of myocardial perfusion with QPS. The authors showed no significant diagnostic differences between studies processed with and without attenuation correction. Moreover, attenuation correction was associated with false-positive results in the left anterior descending artery territory, whereas non-correction was associated with false-positive results in the right coronary artery territory. It becomes clear that the correction for attenuation may induce a bias in images interpretation, and although attenuation artifacts are diminished, some new artifacts can be created from the correction process. $^{29}$ A potential goal might be a combination of quantitative attenuation correction and non-correction analyses to fully realize the potential of myocardial perfusion imaging with automated software, keeping in mind that the currently available quantitative methods can effort to estimate the fraction of myocardium that is ischemic. The stress and rest scores represent rational attempt to graduate the severity of flow reduction with the compromised volume and represent more of an "ischemic burden.," ${ }^{30}$ Therefore, there is still a need to establish a better standard for SPECT myocardial perfusion imaging.

\section{Conflict of interest}

The authors have indicated that they have no financial conflict of interest.

\section{References}

1. Lu CY. Uncertainties in real-world decisions on medical technologies. Int J Clin Pract 2014;68:936-40.

2. Petretta M, Cuocolo A. Prediction models for risk classification in cardiovascular disease. Eur $\mathrm{J}$ Nucl Med Mol Imaging 2012:39:1959-69.

3. Cuocolo A, Petretta M, Acampa W, De Falco T. Gated SPECT myocardial perfusion imaging: The further improvements of an excellent tool. Q J Nucl Med Mol Imaging 2010;54:129-44.

4. Thompson CA. FDA approves pharmacologic stress agent. Am J Health Syst Pharm 2008;65:890.

5. Lieu HD, Shryock JC, von Mering GO, Gordi T, Blackburn B, Olmsted AW, et al. Regadenoson, a selective A2A adenosine receptor agonist, causes dose-dependent increases in coronary blood flow velocity in humans. J Nucl Cardiol 2007;14:514-20.

6. Ghimire G, Hage FG, Heo J, Iskandrian AE. Regadenoson: A focused update. J Nucl Cardiol 2013;20:284-8.

7. Cerqueira MD, Nguyen $P$, Staehr $P$, Underwood SR, Iskandrian AE, ADVANCE-MPI Trial Investigators. Effects of age, gender, obesity, and diabetes on the efficacy and safety of the selective $\mathrm{A} 2 \mathrm{~A}$ agonist regadenoson versus adenosine in myocardial perfusion imaging integrated ADVANCE-MPI trial results. JACC Cardiovasc Imaging 2008;1:307-16.

8. Xu Y, Hayes S, Ali I, Ruddy TD, Wells RG, Berman DS, et al. Automatic and visual reproducibility of perfusion and function measures for myocardial perfusion SPECT. J Nucl Cardiol 2010;17:1050-7.

9. Mahmarian JJ, Cerqueira MD, Iskandrian AE, Bateman TM, Thomas GS, Hendel RC, et al. Regadenoson induces comparable left ventricular perfusion defects as adenosine: A quantitative analysis from the ADVANCE MPI 2 trial. JACC Cardiovasc Imaging 2009;2:959-68.

10. Iskandrian AE, Bateman TM, Belardinelli L, Blackburn B, Cerqueira MD, Hendel RC, et al. Adenosine versus regadenoson comparative evaluation in myocardial perfusion imaging: Results of the ADVANCE phase 3 multicenter international trial. J Nucl Cardiol 2007; 14:645-58.

11. Ficaro EP, Lee BC, Kritzman JN, Corbett JR. Corridor4DM: The Michigan method for quantitative nuclear cardiology. J Nucl Cardiol 2007; 14:455-65.

12. Mahmarian JJ, Peterson LE, Xu J, Cerqueira MD, Iskandrian AE, Bateman TM, et al. Regadenoson provides perfusion results comparable to adenosine in heterogeneous patient populations: A quantitative analysis from the ADVANCE MPI Trials. J Nucl Cardiol (in press).

13. Garcia EV, Cooke CD, Folks RD, Santana CA, Krawczynska EG, De Braal L, et al. Diagnostic performance of an expert system for the interpretation of myocardial perfusion SPECT studies. J Nucl Med 2001;42:1185-91.

14. Petretta M, Cuocolo R, Acampa W, Cuocolo A. Quantification of myocardial perfusion: SPECT. Curr Cardiovasc Imaging Rep 2012;5:144-50.

15. Germano G, Kavanagh PB, Slomka PJ, Van Kriekinge SD, Pollard G, Berman DS. Quantitation in gated perfusion SPECT imaging: The Cedars-Sinai approach. J Nucl Cardiol 2007;14:433-54. 
16. Garcia EV, Faber TL, Cooke CD, Folks RD, Chen J, Santana C. The increasing role of quantification in clinical nuclear cardiology: The Emory approach. J Nucl Cardiol 2007;14:420-32.

17. Wolak A, Slomka PJ, Fish MB, Lorenzo S, Acampa W, Berman DS, et al. Quantitative myocardial-perfusion SPECT: Comparison of three state-of-the-art software packages. J Nucl Cardiol 2008;15:27-34.

18. Ather S, Iqbal F, Gulotta J, Aljaroudi W, Heo J, Iskandrian AE, et al. Comparison of three commercially available softwares for measuring left ventricular perfusion and function by gated SPECT myocardial perfusion imaging. J Nucl Cardiol 2014;21:673-81.

19. Wackers FJ. Call for a standard unit of defect size. J Nucl Cardiol 2014;21:682-4.

20. Iskandrian AE, Hage FG, Shaw LJ, Mahmarian JJ, Berman DS. Serial myocardial perfusion imaging: Defining a significant change and targeting management decisions. JACC Cardiovasc Imaging 2014;7:79-96.

21. Hendel RC, Berman DS, Cullom SJ, Follansbee W, Heller GV, Kiat $\mathrm{H}$, et al. Multicenter clinical trial to evaluate the efficacy of correction for photon attenuation and scatter in SPECT myocardial perfusion imaging. Circulation 1999;99:2742-9.

22. Links JM, DePuey EG, Taillefer R, Becker LC. Attenuation correction and gating synergistically improve the diagnostic accuracy of myocardial perfusion SPECT. J Nucl Cardiol 2002;9:183-7.

23. Masood Y, Liu YH, DePuey G, Taillefer R, Araujo LI, Allen S, et al. Clinical validation of SPECT attenuation correction using Xray computed tomography-derived attenuation maps: Multicenter clinical trial with angiographic correlation. J Nucl Cardiol 2005;12:676-86.
24. Ficaro EP, Fessler JA, Shreve PD, Kritzman JN, Rose PA, Corbett JR. Simultaneous transmission/emission myocardial perfusion tomography: Diagnostic accuracy of attenuation-corrected $99 \mathrm{mTc}-$ sestamibi single-photon emission computed tomography. Circulation 1996;93:463-73.

25. Shotwell M, Singh BM, Fortman C, Bauman BD, Lukes J, Gerson MC. Improved coronary disease detection with quantitative attenuation-corrected Tl-201 images. J Nucl Cardiol 2002;9:52-62.

26. Grossman GB, Garcia EV, Bateman TM, Heller GV, Johnson LL, Folks RD, et al. Quantitative Tc-99m sestamibi attenuation-corrected SPECT: Development and multicenter trial validation of myocardial perfusion stress gender-independent normal database in an obese population. J Nucl Cardiol 2004;11:263-72.

27. Slomka PJ, Fish MB, Lorenzo S, Nishina H, Gerlach J, Berman DS, et al. Simplified normal limits and automated quantitative assessment for attenuation-corrected myocardial perfusion SPECT. J Nucl Cardiol 2006;13:642-51.

28. Wolak A, Slomka PJ, Fish MB, Lorenzo S, Berman DS, Germano G. Quantitative diagnostic performance of myocardial perfusion SPECT with attenuation correction in women. $\mathrm{J}$ Nucl Med 2008;49:915-22.

29. Cuocolo A. Attenuation correction for myocardial perfusion SPECT imaging: Still a controversial issue. Eur J Nucl Med Mol Imaging 2011;38:1887-9.

30. Watson DD. Thoughts on Wackers' call for a standard unit of defect size. J Nucl Cardiol 2014;21:685. 